\title{
In vitro Effect of Silver Nanoparticles on Blastocystis hominis
}

This article was published in the following Dove Press journal:

International Journal of Nanomedicine

\author{
Mohamed Saad Younis (iD) \\ Eman Abd el rahman Abououf' \\ Ali El saeed Ali' \\ Sara Mohamed Abd elhady $\mathbb{D D}^{2}$ \\ Rita Maher Wassef $\left(\mathbb{D}^{2}\right.$ \\ 'Medical Parasitology Department, \\ Faculty of Medicine, Benha University, \\ Benha, Egypt; ${ }^{2}$ Medical Parasitology \\ Department, Faculty of Medicine, Helwan \\ University, Cairo, Egypt
}

Introduction: This study aims to assess the efficacy of silver nanoparticles (Ag Nps) alone and combined with metronidazole $(\mathrm{Ag} \mathrm{Nps}+\mathrm{MTZ})$ as potential alternative therapeutic agents for Blastocystis hominis.

Methods: The parasites were challenged with Ag Nps, Ag Nps + MTZ and MTZ. To assess the efficacy of drugs, counting of viable parasites was done after 1, 2, and 3 hours of adding the drugs.

Results: Blastocystis hominis count was reduced by $20.72 \%, 28.23 \%$, and $18.92 \%$ after one hour of adding Ag Nps, Ag Nps + MTZ, and MTZ, respectively. Cysts count was further reduced by $51.49 \%, 61.61 \%$, and $40.78 \%$ after 2 hours and by $71.69 \%, 79.67 \%$, and $62.65 \%$ after 3 hours of adding the drugs in the same order, respectively.

Conclusion: There was a statistically significant difference $(P<0.05)$ in the in vitro growth inhibition of the parasite over the different time intervals when using the tested drugs against the control drug.

Keywords: Blastocystis hominis, eosin brilliant cresyl blue stain, metronidazole, silver nanoparticles

\section{Background}

B. hominis is a unicellular, obligate, anaerobic protozoan found in the gastrointestinal tract of man; many other vertebrates and invertebrates act as a reservoir host for man. ${ }^{1}$ It has a worldwide distribution and is considered one of the most common human protozoa especially in developing countries with a higher prevalence rate $(30 \%-50 \%)$ than in developed countries $(1.5 \%-10 \%){ }^{2}$ In Egypt, the prevalence has reached up to $50 \%{ }^{3}$ It has four main forms which are vacuolar, granular, and amoeboid forms which can be found in culture and cyst form found in the stool. Transmission of the parasite occurs through the feco-oral route especially in people with poor environmental sanitation with frequent exposure to animals and contaminated food. ${ }^{4} B$. hominis may pass unnoticed or might be accompanied by many symptoms like nausea, vomiting, abdominal cramps, fatigue, and diarrhea especially in children and immunocompromised patients. ${ }^{5}$ Various methods are used for diagnosis of $B$. hominis which are microscopic detection of the parasite in fecal specimens, immunodiagnosis, molecular diagnosis and culture on Jones's media. The latter is considered as the gold standard diagnostic method. ${ }^{6}$ Treatment of infected patients is controversial as the symptoms seem to be self-limited in most of the cases; however, it is crucial in case of persistent diarrhea when no other pathogen could be detected in fecal samples with the presence of debilitating
Correspondence: Rita Maher Wassef Medical Parasitology Department, Faculty of Medicine, Helwan University, 30 Street 276 New Maadi, Cairo, Egypt

Tel +201005782994

Fax +2022519338I

Email rita.wassef@med.helwan.edu.eg
International Journal of Nanomedicine 2020:15 8167-8173

8167 
symptoms. Although metronidazole is considered the first line of treatment of B. hominis, ${ }^{7}$ side effects such as metallic taste, anorexia, nausea, and vomiting may occur. Besides, the regimen of treatment requires a long duration consumption of the drug which may cause headache, vertigo, dizziness, and syncope and sometimes may lead to convulsive seizures, peripheral neuropathy, neutropenia, and leucopenia. Resistance to metronidazole treatment had been also reported since $1976 ;^{8}$ thus, there was a great need to develop a new, safer, and more effective alternative drug.

Nanoparticles are new promising emerging drug carriers that proved to be effective in treating many parasitic diseases through overcoming the poor cellular permeability, nonspecific distribution, low bioavailability, and rapid elimination of antiparasitic agents from the body. They can also be used as antimicrobial agents. Among the different types of nanoparticles used as antimicrobial agents, silver nanoparticles (Ag Nps) have proved to have better efficacy against different microorganisms although the exact mechanism of its action is still unresolved. ${ }^{9}$ A proposed mechanism of parasite growth inhibition is by enhancing the function of the immune system; another suggested mechanism is by inducing morphological and structural changes in the parasites ${ }^{10}$ and another mechanism is by binding to the cell membrane of the infected cell and causing cellular oxidative stress in microbes. ${ }^{11}$

Silver nanoparticles are ideal nanocarriers for antiparasitic drug delivery and have been successfully and effectively used to treat several parasitic infections. ${ }^{12}$ Nevertheless, their effect on B. hominis has not been widely explored yet. Therefore, this study was conducted to detect the effect of silver nanoparticles as a sole agent and as a combination with metronidazole on $B$. hominis in vitro compared to metronidazole.

\section{Methods}

\section{Sample Collection and Processing}

Stool samples were collected from symptomatic patients attending the outpatient clinic of Theodor Bilharz Research Institute (TBRI) in sterile, disposable clean containers labeled with the patient's name and date of collection. They were examined macroscopically ${ }^{13}$ and microscopically for the presence of $B$. hominis and to exclude the presence of other parasites. Microscopic examination of the samples was done by direct wet smear, ${ }^{14}$ iodine stained smear, ${ }^{15}$ and formol ether concentration technique. ${ }^{16}$ Positive samples were further cultured in $5 \mathrm{~mL}$ of modified Jones' media on the same day of collecting the samples. ${ }^{3}$ The culture tubes were incubated at $37^{\circ} \mathrm{C}$ with daily examination for 72 hours. This was done by examining a drop of the supernatant by the low (x10) and high (x40) power fields of a light microscope. Culture tubes were considered negative for $B$. hominis when no parasite growth was detected after $72 \mathrm{~h}$ of culture and incubation. Culture tubes were considered suitable for the assessment of the drug when the parasite number $/ \mathrm{mL}$ exceeded $1 \times 103$ vacuolar forms. ${ }^{17}$

\section{Preparation of the Drugs}

The synthesis procedure of silver nanoparticles (Ag Nps) and silver nanoparticles loaded with metronidazole (Ag Nps + MTZ) used in the current study was adopted from the procedure developed by Steve and Johnson. ${ }^{18}$ The particles were characterized with a transmission electron microscope, and their size distribution had a mean of 40 $\mathrm{nm}$. The surface morphology and size distribution of silver nanoparticles are shown in Figure 1. The concentration used for both drugs was $150 \mu \mathrm{g} / \mathrm{mL}$. The loading capacity (LC) of nanoparticles was calculated according to the Eq. 1:

$$
\% \mathrm{LC}=[(\mathrm{A}-\mathrm{B}) / \mathrm{C}] \times 100
$$

where " $A$ " is the total amount of MTZ, "B" is the free amount of MTZ and "C" is the weight of nanoparticles.

Commercially available metronidazole (MTZ) (Amrizole ${ }^{\circledR}$ injection for intravenous infusion) $0.5 \% \mathrm{w} / \mathrm{v}$ in $100 \mathrm{~mL}$ bottles (500 mg MTZ in $100 \mathrm{~mL}$ ) was

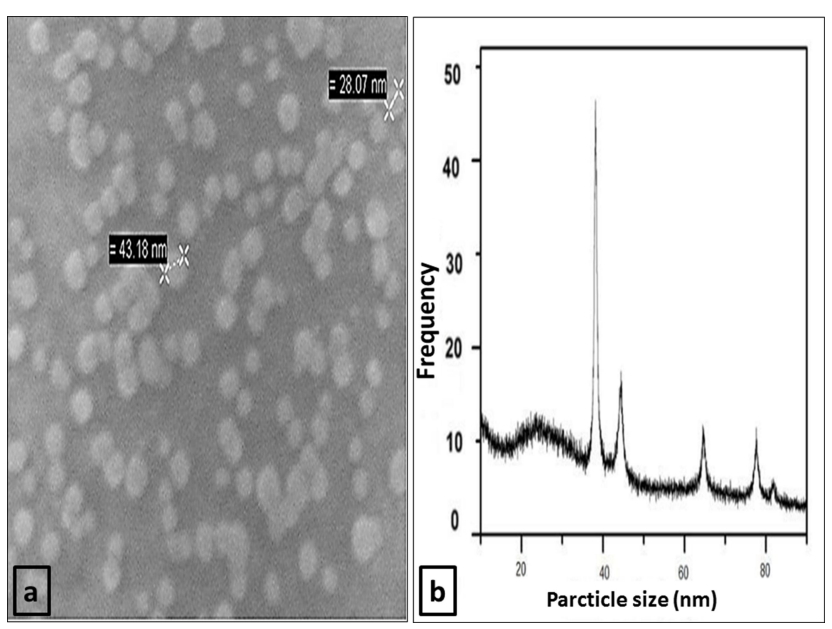

Figure I (A) Transmission electron microscope image showing the surface morphology and image analysis of silver nanoparticles (mean $40 \mathrm{~nm}$ ). (B) Histogram showing the size distribution of silver nanoparticles. 
manufactured and purchased from Amriya for pharmaceutical industries Alexandria, Egypt. It was used as a reference antiprotozoal drug. The drug was protected from light and stored below $30^{\circ} \mathrm{C}$. Sterile distilled water was added to the drug until reaching the required concentration of MTZ that was adjusted to $150 \mu \mathrm{g} / \mathrm{mL}$.

\section{In vitro Anti-Blastocystis Activity of $\mathrm{Ag}$ Nps, Ag Nps + MTZ and MTZ}

Parasite subcultures were done by introducing inoculums from the culture tubes into new sets of culture tubes containing Jones' medium with the tested drugs. Nontreated control cultures of the parasites were also subjected to the same procedure used for the other tested cultures.

Culture tubes were divided into four groups used in triplicate for each drug and the non-treated (control) cultures. Group A was the control group and included culture tubes containing the parasite without treatment; Group B was formed of culture tubes containing the parasite and silver nanoparticles at a concentration of $150 \mu \mathrm{g} / \mathrm{mL}$; Group C was formed of culture tubes containing the parasite and metronidazole loaded with silver nanoparticles at a concentration of $150 \mu \mathrm{g} / \mathrm{mL}$ while Group D included culture tubes containing the parasite and metronidazole drug at a concentration of $150 \mu \mathrm{g} / \mathrm{mL}$. The tested cultures were incubated at $37^{\circ} \mathrm{C}$ and examined after 1,2 , and 3 $\mathrm{h}$. The treatment period of at least $1 \mathrm{~h}$ was used in previous standardized studies and had shown that this period is needed to induce the cytotoxic effect in B. hominis. ${ }^{19}$

Assessment of in vitro Anti-Blastocystis Activity of $\mathrm{Ag}$ $\mathrm{Nps}, \mathrm{Ag} \mathrm{Nps}+\mathrm{MTZ}$ and MTZ

Assessment of the anti-Blastocystis activity of the tested drugs was carried out by counting the number of viable cells after 1, 2, and $3 \mathrm{~h}$ using eosin-brilliant cresyl blue dye which stained viable cells with green color and nonviable cells with red color. ${ }^{20}$ Counting the number of viable cells was done in duplication using a Neubauer cell counting chamber under a light microscope. The percentage of growth inhibition of $B$. hominis in the treated cultures to the nontreated cultures was calculated according to the Eq. 2:

$$
\text { Growth inhibition }(\%)=\frac{a-b}{a} \times 100
$$

where "a" is the mean number of parasites in control cultures and "b" is the mean number of parasites in treated cultures.

\section{Statistical Analysis}

Data were coded and entered using the statistical package for the Social Sciences (SPSS) version 26 (IBM Corp., Armonk, NY, USA). Data were summarized using mean and standard deviation for quantitative variables. Comparisons between groups were done using analysis of variance (ANOVA) with multiple comparisons post hoc test. ${ }^{21} P$-values less than 0.05 were considered statistically significant.

\section{Ethical Consideration}

This study was performed in line with the principles of the Declaration of Helsinki. The protocol of this study was approved by the scientific research ethics committee of the Faculty of Medicine, Benha University. Patients included in the study were informed verbally about the purpose of the study and the collection of stool samples was performed after obtaining their consent. The informed verbal consent process was approved by TBRI Research Ethics Committee.

\section{Results}

The growth of $B$. hominis was inhibited after adding silver nanoparticles, metronidazole loaded with silver nanoparticles, and metronidazole to the culture tubes with all drugs used at a concentration of $150 \mu \mathrm{g} / \mathrm{mL}$. This inhibition was directly proportional to the time of exposure to the drug (Figures 2-4).

B. hominis cysts count was reduced by $20.72 \%$, $28.23 \%$, and $18.92 \%$ after one hour of adding silver nanoparticles, metronidazole loaded with silver nanoparticles, and metronidazole, respectively. The decrease in all groups compared to the control after the first hour was statistically significant $(P<0.05)$.

A further significant decrease in the parasitic count was noted in all groups compared to the non-treated control group after 2 and 3 hours of adding the drug $(P<0.001)$; the number dropped by $51.49 \%, 61.61 \%$, and $40.78 \%$ after 2 hours with silver nanoparticles, metronidazole loaded with silver nanoparticles and metronidazole, respectively, and dropped again by $71.69 \%, 79.67 \%$, and $62.65 \%$ after 3 hours of adding the drugs in the same orders. The effect of different drugs on the growth of $B$. hominis is illustrated in Table 1. The greatest effect on $B$. hominis was seen when using metronidazole loaded with silver nanoparticles (Figure 5). 


\section{Count of $B$. hominis after 1, 2 and 3 hours of adding the silver nanoparticles}

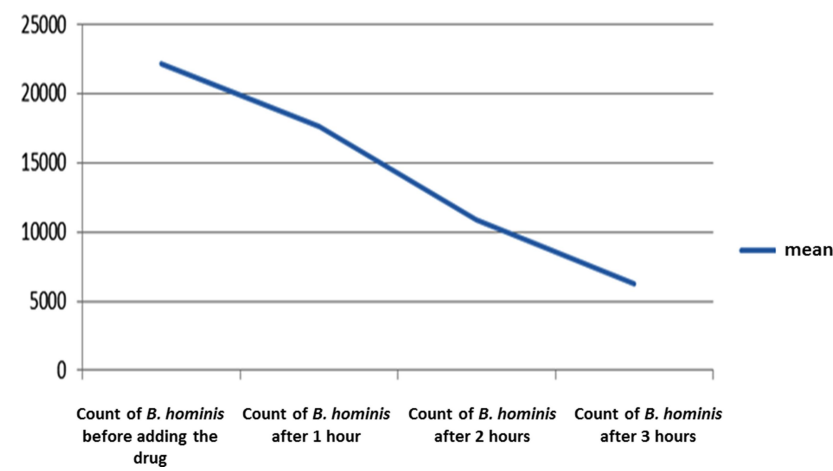

Figure 2 Means of the count of B. hominis after 1,2 and 3 hours of adding silver nanoparticles in vitro.

\section{Count of B. hominis after 1, 2 and 3 hours of adding metronidazole loaded with silver nanoparticles}

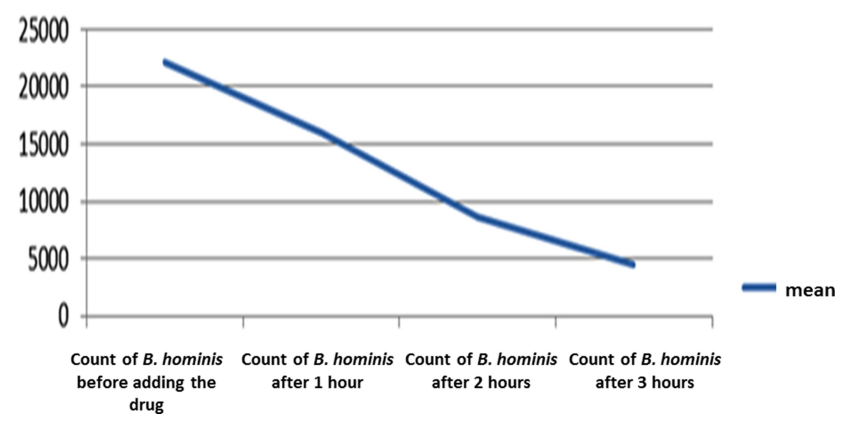

Figure 3 Means of the count of B. hominis after I, 2 and 3 hours of adding metronidazole loaded with silver nanoparticles in vitro.

\section{Discussion}

Metronidazole is the first line of treatment of $B$. hominis. ${ }^{7}$ However, side effects, treatment failure, and resistance to metronidazole had been reported since 1976 and similar cases of treatment failure were reported later on. ${ }^{8}$ Therefore, a great need to develop newer and safer antiparasitic agents has emerged.

New approaches such as nanobiotechnology are used nowadays in the treatment of different parasitic infections. The use of nanobiotechnology in the treatment of parasitic diseases is due to the unique properties of nanoparticles as the size of nanomaterials reaches $(10-100) \mathrm{nm}$ which is similar to the size of most biological structures, so enhance the penetration of the drug to various tissues of the body. ${ }^{22}$ A study has suggested the occurrence of interaction between the nanoparticles and the surface of parasites, as the nanoparticles impair the structure of glycoprotein and lipophosphoglycan molecules which are present on the surface of parasites and are responsible for the infection. $^{23}$ They also proposed that the nanoparticles release Reactive Oxygen Species (ROS) which have serious effects on these molecules; thus, they become able to kill the infectious agents leading to termination of the parasitic infection. The authors declared that the main reason for using silver nanoparticles $(\mathrm{Ag} \mathrm{Nps})$ in their study was the ability of (Ag Nps) to produce reactive oxygen species (ROS) which have an inhibitory effect on ATP production and DNA replication. ${ }^{23}$

The current study was carried out during the period from February 2019 to February 2020; stool samples were collected from patients attending outpatient clinics of Theodor Bilharz Research Institute (T.B.R.I), Giza, Egypt, suffering from gastrointestinal symptoms. By microscopic examination, specimens proved to be infected with $B$. hominis were collected and immediately cultured on Jones' media. Assessment of the effect of silver nanoparticles at a concentration of $(150 \mu \mathrm{g} / \mathrm{mL})$, metronidazole loaded with silver nanoparticles at a concentration of (150 $\mu \mathrm{g} / \mathrm{mL}$ ) on Blastocystis hominis in vitro in comparison to metronidazole at a concentration of $(150 \mu \mathrm{g} / \mathrm{mL})$ was performed after 1 hour, 2 hours, and 3 hours.

The results indicate a significant reduction in the B. hominis count by $(20.72 \%, 28.23 \%, 18.92 \%)$ after 1 hour of adding silver nanoparticles, metronidazole loaded with silver nanoparticles, and metronidazole, respectively, with an unvarying concentration of $(150 \mu \mathrm{g} / \mathrm{mL})$.

Moreover, the reduction was $(51.49 \%, 61.61 \%$, $40.78 \%$ ) after 2 hours and $(71.69 \%, 79.67 \%, 62.65 \%)$ after 3 hours of adding silver nanoparticles, metronidazole loaded with silver nanoparticles, and metronidazole, respectively. All drugs used were at an even concentration of $(150 \mu \mathrm{g} / \mathrm{mL})$.

These results are in agreement with the sole previous study that investigated the inhibitory activity of various concentrations of silver nanoparticles and curcumin nanoparticles (Cur Nps) on B. hominis in vitro. The effect of $\mathrm{Ag}$ Nps and Cur Nps was significantly higher than that detected for MTZ through different incubation periods. However, it concluded that the effect of the single therapy was better than the combined Cur Nps + Ag Nps. ${ }^{17}$ The main difference between this study and our current study is in the incubation period and the time required for drug assessment. In that study, the researchers examined the culture after 72 hours while in our study we examined 


\section{Count of B. hominis after 1, 2 and 3 hours of adding metronidazole}

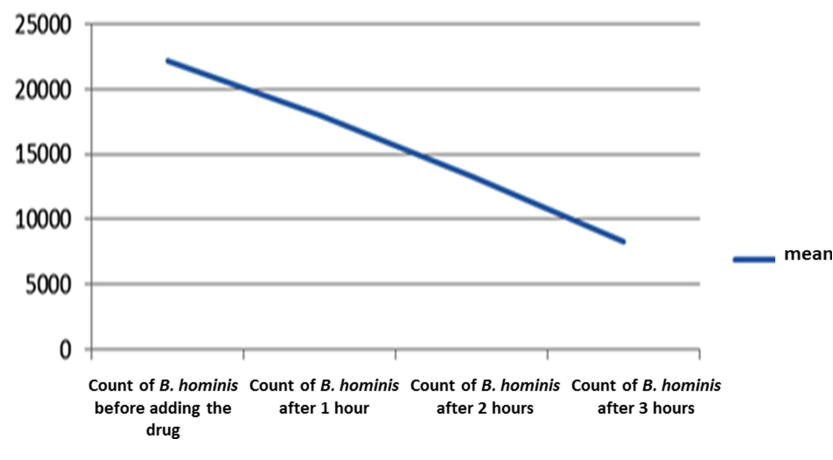

Figure 4 Means of the count of B. hominis after I, 2 and 3 hours of adding metronidazole in vitro.

the cultures after 1, 2, and 3 hours. That is because Ag Nps nanoparticles showed anti-parasitic activity on other protozoa like Entamoeba histolytica and Cryptosporidium parvum with high mortality rates after only $180 \mathrm{~min}$ of exposure time to Ag Nps. ${ }^{24}$ In another study, when MTZ was used in vitro at concentrations of 150 and $250 \mu \mathrm{g} / \mathrm{mL}$, there was a significant growth inhibition and Apoptotic like changes of $B$. hominis after 1 and 2 hours. ${ }^{25}$ Similarly, Ag Nps showed significant anti-leishmanial effects by inhibiting the promastigotes proliferation and metabolic activity, with the highest suppressive effect on parasites at a concentration of $(200 \mu \mathrm{g} / \mathrm{mL}) .{ }^{26}$ Additionally, according to a previous study, the use of silver nanoparticles between 100 and $200 \mu \mathrm{g} / \mathrm{mL}$ proved to be safe in the experimental animals as all the values of silver detected in different tissues were within the safe range in the experiment. ${ }^{10}$ Therefore, the current study was designed to assess the viability of $B$. hominis when challenged with $\mathrm{Ag}$ Nps and Ag Nps +MTZ at a concentration of $150 \mu \mathrm{g} / \mathrm{mL}$ for 1,2 , and 3 hours.

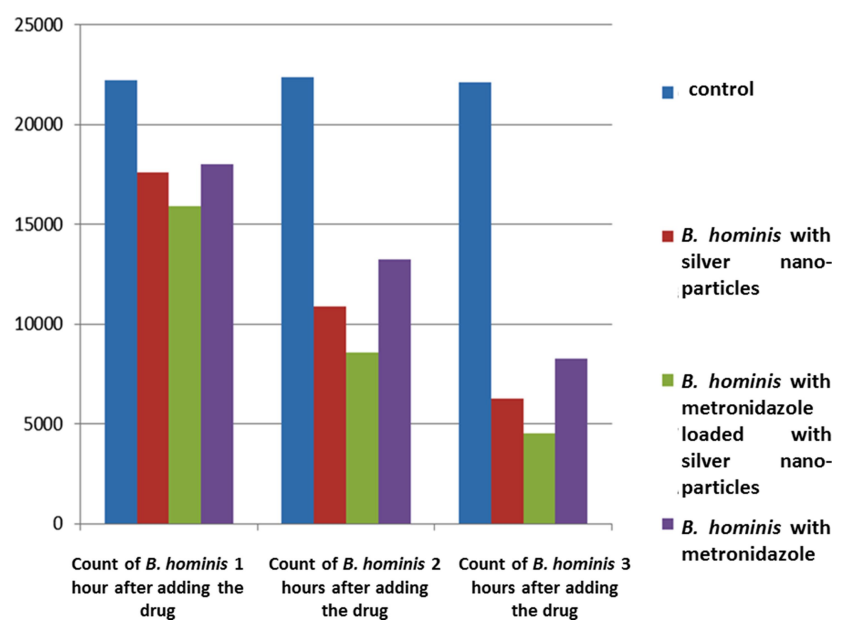

Figure 5 Difference of the effect of different drugs on the count of $B$. hominis over the hours.

Silver nanoparticles have been proven to have many inhibitory and cytotoxic effects on many parasites such as Giardia, Toxoplasma, Leishmania, Plasmodium, and even insect larvae. ${ }^{27}$ One study examined the disinfection ability of Ag Nps on Cryptosporidium parvum oocysts in vitro and confirmed the results by in vivo study. The researchers detected nearly two orders of magnitude reduction in oocyst shedding in mice fed on Ag Nps treated oocysts when compared with the control group. ${ }^{28}$ Likewise, another study showed that both silver nanoparticles and silver ions significantly decrease Cryptosporidium oocysts viability, in a dose-dependent manner, between concentrations of 0.005 and $500 \mu \mathrm{g} / \mathrm{mL}$, as assessed by an excystation assay and the shell/sporozoite ratio, the results were statistically significant at 500 and $5000 \mu \mathrm{g} / \mathrm{mL}^{29}$

The effects of Ag Nps and Chitosan were studied to evaluate their anti-Toxoplasma effects singly or combined as treatment and as prophylaxis in the experimental animals and the results showed that silver nanoparticles used singly or combined with chitosan have anti-toxoplasma

Table I Effect of Ag Nps, Ag Nps + MTZ and MTZ on the in vitro Growth of B. hominis After Different Incubation Periods, Drugs/ Concentration $(\mu \mathrm{g} / \mathrm{mL})$

\begin{tabular}{|c|c|c|c|c|}
\hline $\begin{array}{l}\text { Groups (Drugs/ } \\
\text { Concentration }(\mu \mathrm{g} / \mathrm{mL}))\end{array}$ & $\begin{array}{l}\text { Control } \\
\text { Group }\end{array}$ & $\begin{array}{l}\text { B. hominis with (Ag } \\
\text { Nps I50 } \mu \mathrm{g} / \mathrm{mL} \text { ) Group }\end{array}$ & $\begin{array}{l}\text { B. hominis with Ag Nps + MTZ } \\
(150 \mu \mathrm{g} / \mathrm{mL}) \text { Group }\end{array}$ & $\begin{array}{l}\text { B. hominis with MTZ } \\
\text { (150 } \mathrm{gg} / \mathrm{mL}) \text { Group }\end{array}$ \\
\hline $\begin{array}{l}\text { (Cells } / \mathrm{mL}) \text { Mean } \pm \text { SD } \\
\text { (Ihour) } \\
\text { (Cells } / \mathrm{mL}) \text { Mean } \pm \text { SD } \\
\text { (2hours) } \\
\text { (Cells } / \mathrm{mL} \text { ) Mean } \pm \text { SD } \\
\text { (3hours) }\end{array}$ & $\begin{array}{l}(22200.00) \pm \\
2107.13 \\
(22400.00) \pm \\
2306.51 \\
(22133.33) \pm \\
2013.29\end{array}$ & $\begin{array}{l}(17600.00) \pm 1928.73 * \\
(20.72 \%) \\
(10866.67) \pm 808.29 *(51.49 \%) \\
(6266.67) \pm 808.29 *(71.69 \%)\end{array}$ & $\begin{array}{l}(15933.33) \pm 1814.75 *(28.23 \%) \\
(8600.00) \pm 600.00 *(61.61 \%) \\
(4533.33) \pm 757.19 *(79.67 \%)\end{array}$ & $\begin{array}{l}(I 8000.00) \pm 1509.97 * \\
(18.92 \%) \\
(13266.67) \pm 702.38^{*} \\
(40.78 \%) \\
(8266.67) \pm 1101.5 I^{*} \\
(62.65 \%)\end{array}$ \\
\hline
\end{tabular}

Notes: Values are expressed as mean \pm SD and Growth Inhibition (\%) from control. *Statistically significant difference compared to infection control group ( $\mathrm{P}<0.05$ ). 
potentials. In different tissues, the amount of silver detected was within the safe range. Thus, these nanoparticles proved their effectiveness against the experimental Toxoplasma infection. ${ }^{10}$ Similarly, another study investigated the effectiveness of Ag Nps on Leishmania tropica in both stages amastigote and promastigote, and in comparison to pentostam as a control drug in vitro, it showed the effects of Ag Nps when compared to pentostam at different concentrations. ${ }^{30}$

The data presented here allow us to confidently propose the use of silver nanoparticles and metronidazoleloaded silver nanoparticles as highly efficient alternative therapy against $B$. hominis infection. Nevertheless, to better understand the mechanism of inhibition and whether these particles induce ultrastructural or immunological changes to the parasite, more studies are still needed. Besides, as cytotoxicity associated with nanotechnology is still raising certain concerns, we recommend conducting further in vivo studies of the combined drug at the current concentration to address this issue.

\section{Data Sharing Statement}

All data are available from the corresponding author upon request.

\section{Acknowledgments}

The authors deeply appreciate the support given by Prof. Dr Ibrahim Rabee Bayoumi Professor of Immunoparasitology, Immunology and Evaluation of Drug Department, Theodor Bilharz Research Institute (TBRI) for his unlimited effort in the preparation of silver nanoparticles.

\section{Author Contributions}

All authors made substantial contributions to conception and design, acquisition of data, or analysis and interpretation of data; took part in drafting the article or revising it critically for important intellectual content; agreed to submit to the current journal; gave final approval of the version to be published; and agree to be accountable for all aspects of the work.

\section{Funding}

This research did not receive any specific grant from funding agencies in the public, commercial, or not-forprofit sectors.

\section{Disclosure}

The authors declared that there were no potential conflicts of interest concerning the research, authorship, and/or publication of this article.

\section{References}

1. Yan Y, Su S, Ye J, et al. Blastocystis sp. subtype 5: a possibly zoonotic genotype. Parasitol Res. 2007;101(6):1527-1532. doi:10.1007/s00436-007-0672-y

2. Eassa SM, Ali HS, El Masry SA, Abd El-fattah AH. Blastocystis hominis among immunocompromised and immunocompetent children in Alexandria, Egypt. Ann Clin Lab Sci. 2016;4(2):2-92.

3. Hassan MA, Rizk EA, Wassef RM. Modified culture methodology for specific detection of Blastocystis hominis in stool samples. J Egypt Soc Parasitol. 2016;46(3):541-548. doi:10.12816/0033974

4. Coyle CM, Varughese J, Weiss LM, Tanowitz HB. Blastocystis: to treat or not to treat. Clin Infect Dis. 2012;54(1):105-110. doi: $10.1093 / \mathrm{cid} / \mathrm{cir} 810$

5. Sari IP, Benung MR, Wahdini S, Kurniawan A. Diagnosis and identification of blastocystis subtypes in primary school children in Jakarta. J Trop Pediatr. 2018;117(8):2585-2590.

6. Elghareeb AS, Younis MS, El Fakahany AF, Nagaty IM, Nagib MM. Laboratory diagnosis of Blastocystis spp. In diarrheic patients. Trop Parasitol. 2015;5(1):36-41. doi:10.4103/2229-5070.149919

7. Sekar U, Shanthi M. Blastocystis: consensus of treatment and controversies. Trop Parasitol. 2013;3(1):35-39. doi:10.4103/22295070.113901

8. Rajamanikam A, Kumar S, Samudi C, Kudva M. Exacerbated symptoms in Blastocystis sp.-infected patients treated with metronidazole: two case studies. J Trop Pediatr. 2018;64(3).

9. Ferdous Z, Nemmar A. Health impact of silver nanoparticles: a review of the biodistribution and toxicity following various routes of exposure. Int J Mol Sci. 2020;21(7):2375. doi:10.3390/ijms 210 72375

10. Gaafar MR, Mady RF, Diab RG, Shalaby TI. Chitosan and silver nanoparticles: promising anti-toxoplasma agents. Exp Parasitol. 2014;143:30-38. doi:10.1016/j.exppara.2014.05.005

11. Abaza SM. Applications of nanomedicine in parasitic diseases. Parasitol United J. 2016;9:1-6. doi:10.4103/1687-7942.192997

12. Sun Y, Chen D, Pan Y, et al. Nanoparticles for antiparasitic drug delivery. Drug Deliv. 2019;26(1):1206-1221. PMID: 31746243; PMCID: PMC6882479. doi:10.1080/10717544.2019.1692968

13. Johnstone N. Macroscopic examination of the feces. J Osteopath (Kirksvill). 1950;57(10):20-21.

14. Cheesbrough M. Medical Laboratory Manual for Tropical Countries. Britain: Butterworth Heinemann Ltd.; 1991:175-185.

15. King M. A Medical Laboratory for Developing Countries. Vol. 15. ELBS, Oxford University Press; 1975:45-55.

16. Cheesbrough M. Medical Laboratory Manual for Tropical Countries. Tropical Health Technology. Vol. 88. Butterworth-Heinemann; 1987:365-389.

17. Ahmed MAF, Ismail KA, Ahmed SAEG, Ibrahim AN, Gohar YM. In vitro activity of curcumin and silver nanoparticles against Blastocystis hominis. Infect Dis Clin Pract. 2015;23:135-140. doi:10.1097/IPC.0000000000000242

18. Solomon SD, Bahadory M, Jeyarajasingam AV, et al. Synthesis and study of silver nanoparticles. J Chem Educ. 2007;84(2):322-325. doi:10.1021/ed084p322

19. Stenzel DJ, Boreham PFL. Blastocystis hominis revisited. Clin Microbiol Rev. 1996;9:563-584. doi:10.1128/CMR.9.4.563

20. Yang LQ, Singh M, Yap EH, et al. In vitro response of Blastocystis hominis against traditional Chinese medicine. J Ethnopharmacol. 1996;55:35-42. doi:10.1016/S0378-8741(96)01471-7 
21. Chan YH. Biostatistics102: quantitative data - parametric \& nonparametric tests. Singapore Med J. 2003;44(8):391-396.

22. Norouzi R. A review on most nanoparticles applied against parasitic infections. J Biol Todays World. 2017;6(10):196-203.

23. Choi $\mathrm{O}, \mathrm{Hu} Z$. Size dependent and reactive oxygen species related nanosilver toxicity to nitrifying bacteria. Environ Sci Technol. 2008;42(12):4583-4588. doi:10.1021/es703238h

24. Saad H, Soliman MI, Azzam AM, Mostafa B. Antiparasitic activity of silver and copper oxide nanoparticles against entamoeba histolytica and cryptosporidium parvum cysts. J Egypt Soc Parasitol. 2015;45(3):593-602. doi:10.12816/0017920

25. El-sayed SH, Amer N, Ismai $\mathrm{S}$, et al. In vitro and in vivo anti-blastocystis efficacy of olive leaf extract and bee pollen compound. Res J Parasitol. 2017;12:33-44. doi:10.3923/jp.2017.33.44

26. Allahverdiyev AM, Kon KV, Abamor ES, Bagirova M, Rafailovich M. Coping with antibiotic resistance: combining nanoparticles with antibiotics and other antimicrobial agents. Expert Rev Anti Infect Ther. 2011;9(11):1035-1052. doi:10.1586/eri.11.121
27. Elmi T, Gholami S, Fakhar M, Azizi F. A review on the use of nanoparticles in the treatment of parasitic infections. $J$ Mazand Univ Med Sci. 2013;23(102):126-133.

28. Su YH, Tsegaye M, Varhue W, et al. Quantitative dielectrophoretic tracking for characterization and separation of persistent subpopulations of Cryptosporidium parvum. Analyst. 2014;139:66-73. doi:10.1039/C3AN01810E

29. Cameron P, Gaiser BK, Bhandari B, et al. Silver nanoparticles decrease the viability of cryptosporidium parvum oocysts. Appl Environ Microbiol. 2015;82(2):431-437.

30. Gharby MA, AL-Qadhi BN, Jaafar SM. Evaluation of silver nanoparticles (Ag NPs) activity against the viability of Leishmania tropica promastigotes and amastigotes in vitro. Iraqi $J$ Sci. 2017;58 (1):13-21.
International Journal of Nanomedicine

\section{Publish your work in this journal}

The International Journal of Nanomedicine is an international, peerreviewed journal focusing on the application of nanotechnology in diagnostics, therapeutics, and drug delivery systems throughout the biomedical field. This journal is indexed on PubMed Central, MedLine, CAS, SciSearch ${ }^{\mathbb{B}}$, Current Contents ${ }^{\mathbb{B}} /$ Clinical Medicine, $^{2}$
Dovepress

Journal Citation Reports/Science Edition, EMBase, Scopus and the Elsevier Bibliographic databases. The manuscript management system is completely online and includes a very quick and fair peer-review system, which is all easy to use. Visit http://www.dovepress.com/ testimonials.php to read real quotes from published authors. 